\title{
The properties of AlGaN epi layer grown by HVPE
}

\author{
Se-Gyo Jung, Hunsoo Jeon, Gang Seok Lee, Seon Min Bae, Wi II Yun, Kyoung Hwa Kim, Sam \\ Nyung Yi, Min Yang, Hyung Soo $\mathrm{Ahn}^{\dagger}$, Suck-Whan Kim*, Young-Moon Yu**, Seong Hak Cheon*** \\ and Hong Ju Ha*** \\ Department of Appied Science, Korea Maritime Universyty, Busan 606-791, Korea \\ *Department of Physics, Andong National University, Andong 760-749, Korea \\ **Pukyong National University LED-Marine Convergence Technology R\&BD Center, Busan 608-739, Korea \\ ***Cs Solution. Co., Ltd., Busan 619-961, Korea
}

(Received October 14, 2011)

(Revised December 17, 2011)

(Accepted December 30, 2011)

\begin{abstract}
The AlGaN layer has direct wide bandgaps ranging from 3.4 to $6.2 \mathrm{eV}$. Nowadays, it is becoming more important to fabricate optical devices in an UV region for the many applications. The high quality AlGaN layer is necessary to establish the UV optical devices. However, the growth of AlGaN layer on GaN layer is difficult due to the lattice mismatch and difference thermal expansion coefficient between GaN layer and AlGaN layer. In this paper, we attempted to grow the LED structure on GaN template by mixed-source HVPE method with multi-sliding boat system. We tried to find the optical and lattice transition of active layer by control the Al content in mixed-source. For the growth of epi layer, the $\mathrm{HCl}$ and $\mathrm{NH}_{3}$ gas were flowed over the mixed-source and the carrier gas was $\mathrm{N}_{2}$. The temperature of source zone and growth zone was stabled at 900 and $1090^{\circ} \mathrm{C}$, respectively. After the growth, we performed the x-ray diffraction (XRD) and electro luminescence (EL) measurement.
\end{abstract}

Key words Hydride vapor phase epitaxy (HVPE), AlGaN, Light emitting diode (LED), x-Ray diffraction (XRD), Electro luminescence (EL), Double heterostructure (DH)

\section{HVPE에 의해 성장된 AlGaN epi layer의 특성}

정세교, 전헌수, 이강석, 배선민, 윤위일, 김경화, 이삼녕, 양민, 안형수 ${ }^{\dagger}$ 김석환*, 유영문**, 천성학***, 하홍주 $* * *$

한국해양대학교 응용과학과, 부산, 606-791

*안동대학교 물리학과, 안동, 760-749

***부경대학교 LED-해양융합기술연구센터, 부산, 608-739

***Cs Solution. Co., Ltd., 부산, 619-961

(2011년 10월 14일 접수)

(2011년 12월 17일 심사완료)

(2011년 12월 30일 게재확정)

요 약 $\mathrm{AlGaN}$ 는 3.4 6.2 $\mathrm{eV}$ 까지 넓은 밴드갭을 가지는 직접천이형 반도체이다. 최근에 자외영역의 광소자가 다양하게 응용되면서 자외선 발광이 가능한 $\mathrm{AlGaN}$ 역시 주목받고 있다. 이를 위해서는 고품질의 $\mathrm{AlGaN}$ 층이 필요하지만 $\mathrm{GaN}$ 층 위에 $\mathrm{AlGaN}$ 층을 성장하는 것은 이들의 격자상수와 열팽창계수 차이로 인해 어렵다. 본 논문에서, multi-sliding boat법이 적용된 혼합소스 $\mathrm{HVPE}$ 법을 이용하여 $\mathrm{GaN}$ template 위에 $\mathrm{LED}$ 구조를 성장하였다. 활성층의 $\mathrm{Al}$ 조성을 조절함으로써 $\mathrm{AlGaN}$ 의 격자상수 변화와 광학적 변화를 관찰하고자 하였다. 에피 성장을 위해 $\mathrm{HCl}$ 과 $\mathrm{NH}_{3}$ 가스를 혼합소스 표면으로 흘 려주었고, 수송가스로는 $\mathrm{N}_{2}$ 를 사용하였다. 소스영역과 성장영역의 온도는 각각 900 과 $1090^{\circ} \mathrm{C}$ 로 안정화하였다. 성장 후 샘 플은 x-ray diffraction(XRD)과 electro luminescence(EL) 측정을 하였다.

\footnotetext{
Corresponding author

Tel: +82-51-410-4781

Fax: +82-51-404-3986

E-mail: ahnhs@hhu.ac.kr
} 


\section{1. 서 론}

III-V족 화합물 반도체 중 하나인 $\mathrm{AlGaN}$ 는 wurtzite 구조의 직접 천이형 물질로, 넓은 에너지 밴드갭을 가지 며 $\mathrm{Al}$ 의 조성비에 따라 $3.4 \mathrm{eV}$ 에서 $6.4 \mathrm{eV}$ 까지 밴드갭 조절이 가능하다. 최근 자외 영역의 빛이 각종 검출기, 살균기 등 여러 분야에 응용되면서 자외 영역의 발광 실 현이 가능한 $\mathrm{AlGaN}$ 을 활성층으로하는 광소자 역시 주 목 받고 있다[1,2].

$\mathrm{AlGaN}$ 를 이용한 광소자를 자외선 응용분야에 적용하 기 위해서는 고품질의 $\mathrm{AlGaN}$ 결정으로 이루어진 활성층 이 필요하지만 $\mathrm{GaN}$ 결정 위에 성장 시 격자상수 차이로 인한 부정합과 열팽창계수 차이로 인하여 인장 변형이 발생하므로 성장이 어려운 것이 사실이다[3]. 이 때문에 $\mathrm{Al}$ 조성비의 제어로 결함밀도를 감소시키고 인장변형을 감소시킨 고품질의 $\mathrm{AlGaN}$ 활성층의 성장이 요구된다.

본 논문에서는 multi-sliding boat법이 적용된 혼합소스 $\mathrm{HVPE}$ 법으로 $\mathrm{AlGaN}$ 층을 활성층으로 하는 $\mathrm{DH}$ (double heterostructure)를 선택 성장하였다. 기존의 HVPE법으 로 $\mathrm{AlGaN}$ 를 성장할 경우 $\mathrm{Al}$ 소스와 $\mathrm{Ga}$ 소스 각각에 $\mathrm{HCl}$ 가스 공급을 위한 관이 필요하여 장비 구조가 복잡 해지며 $\mathrm{AlN}$ 와 $\mathrm{GaN}$ 가 무작위로 반응하여 $\mathrm{AlGaN}$ 가 생 성되므로 $\mathrm{Al}$ 조성비를 조절하기 어렵다는 단점이 있다. 이러한 단점을 보완하고자 $\mathrm{Al}$ 과 $\mathrm{Ga}$ 금속 소스를 하나의 보트에 혼합한 혼합소스를 적용하여 장비의 구조를 보다 간소화 하였으며 $\mathrm{Al}$ 첨가량의 조절로 $\mathrm{Al}$ 조성비가 서로 다른 $\mathrm{AlGaN}$ 층을 성장하였다.

\section{2. 실험방법}

혼합소스를 만들기 위해 $\mathrm{Ga}$ 을 제외한 금속 $\mathrm{Al}$ 과 $\mathrm{n}$ type dopant인 $\mathrm{Te}$, p-type dopant인 $\mathrm{Mg}$ 을 $\mathrm{HCl}$ 과 $\mathrm{DI}$ water의 비율이 $1: 3$ 인 용액에 표면을 에칭 한 후 $\mathrm{DI}$

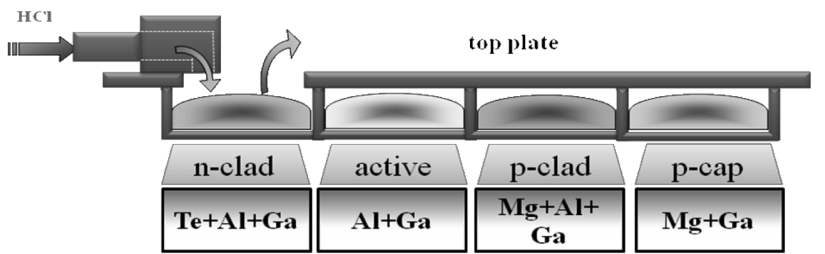

Fig. 1. The schematic of multi-sliding boat with mixed-source.

water에 세척하였다. 세척한 금속 소스들은 Fig. 1에 나 타낸 바와 같이 multi-sliding boat의 각 well에 한꺼번 에 넣어 혼합하였다. 소스의 혼합과정에서 발생할 수 있 는 불순물을 제거하여 고순도의 박막을 얻기 위해 $900^{\circ} \mathrm{C}$ 의 $\mathrm{HVPE}$ 반응관 내에서 2 시간 동안 열처리하여 혼합 하였다.

$\mathrm{DH}$ 를 성장하기 위해 c-sapphire위에 유기금속화학기상증 착법(MOCVD: Metal Organic Chemical Vapor Deposition) 으로 성장된 undoped-GaN 기판을 아세톤과 메탄올에 유기 세척한 후 $\mathrm{HF}$ 용액에 1 분 동안 식각하여 산화막을 제거하였다.

혼합소스 내의 $\mathrm{Al}$ 함량 차이에 따른 $\mathrm{AlGaN}$ 층의 변화 를 알아보고자 활성층을 성장하기 위한 혼합소스에서 $\mathrm{Ga} 20 \mathrm{~g}$ 당 $\mathrm{Al}$ 의 첨가량을 $0.1,0.4,0.6 \mathrm{~g}$ 으로 조절하여 각각을 활성층으로 가지는 $\mathrm{DH}$ 를 성장하였다. $\mathrm{HVPE}$ 장 비의 소스영역과 성장영역의 온도를 각각 $900^{\circ} \mathrm{C}$ 와 $1090^{\circ} \mathrm{C}$ 로 설정하여 안정화 하였다. 성장을 위하여 혼합 소스 표면에 $\mathrm{HCl}$ 을 $20 \mathrm{sccm}, \mathrm{NH}_{3}$ 를 $800 \mathrm{sccm}$ 흘려주 면서 성장하였고, 수송 가스는 $\mathrm{N}_{2}$ 만 사용하였다. p-cap 층을 제외한 모든 층은 각각 10 분간 성장하였고, $\mathrm{p}$-cap 층은 40 초 동안 성장하였다.

\section{3. 실험결과 및 논의}

선택성장된 $\mathrm{DH}$ 의 단면과 표면 관찰을 위해 $\mathrm{SEM}$ 측
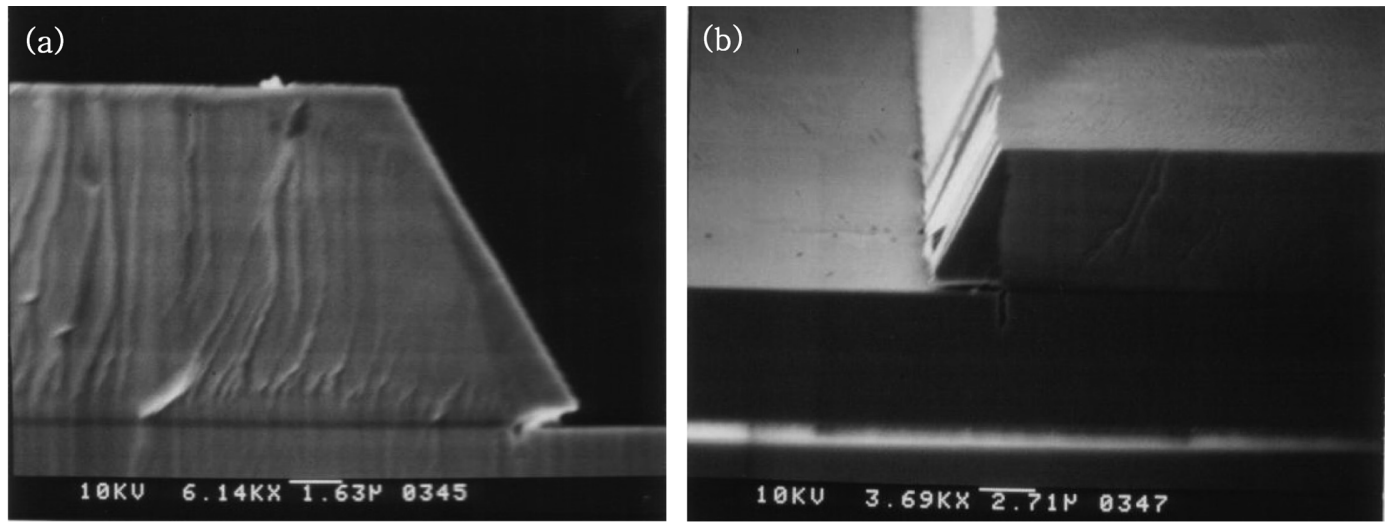

Fig. 2. The SEM images of double heterostructure grown on undoped-GaN. 
정을 하여 그 결과를 Fig. 2에 나타내었다. SEM 측정으 로는 각 층의 두께는 확인하기는 어려웠으나, Fig. 2의 (b)에서 선택 성장된 표면은 아주 깨끗하다는 것을 볼 수 있었다. 최종 성장된 $\mathrm{DH}$ 의 두께가 $9.8 \mu \mathrm{m}$ 이고 총 성장 시간이 30 분 40 초 이므로 평균 성장률은 $0.32 \mu \mathrm{m} /$ $\min$ 임을 볼 수 있다. 일반적인 $\mathrm{HVPE}$ 의 성장률이 $2 \mu \mathrm{m}$ 정도 임을 볼 때 10 배 정도의 감소된 성장률을 얻을 수 있고, 이는 multi-sliding boat법이 적용된 혼합소스 $\mathrm{HVPE}$ 방법이 $\mathrm{DH}$ 와 같은 소자 성장에 적당함을 잘 알 수 있다[7-10].

$\mathrm{Al}$ 조성비에 따른 $\mathrm{AlGaN}$ 층의 격자상수 변화를 알아 보고자 XRD 측정을 시행하였고 그 결과를 Fig. 3에 나 타내었다. GaN peak는 본 연구에서 사용한 HVPE법으 로 성장한 $\mathrm{GaN}$ 의 (0002)면에 대한 것이고 $2 \theta=34.76$ 에 서 나타났다. XRD 측정에서 $\mathrm{Al}$ 첨가량이 증가함에 따 라 $\mathrm{AlGaN}$ 의 peak가 $\mathrm{GaN}$ peak로부터 분리되어 멀어지 며 반치폭 또한 증가하는 것을 볼 수 있었다. 이는 $\mathrm{AlGaN}$ 층에서 $\mathrm{Al}$ 조성비가 증가할수록 격자상수가 감소 하여 $\mathrm{GaN}$ 와 $\mathrm{AlGaN}$ 간의 격자 부정합이 커지기 때문에 $\mathrm{AlGaN}$ 박막이 인장 응력을 받은 영향으로 판단된다 $[4,5] . \mathrm{Al}$ 의 첨가 함량에 따라 변하는 $\mathrm{AlGaN}$ 의 (0002)

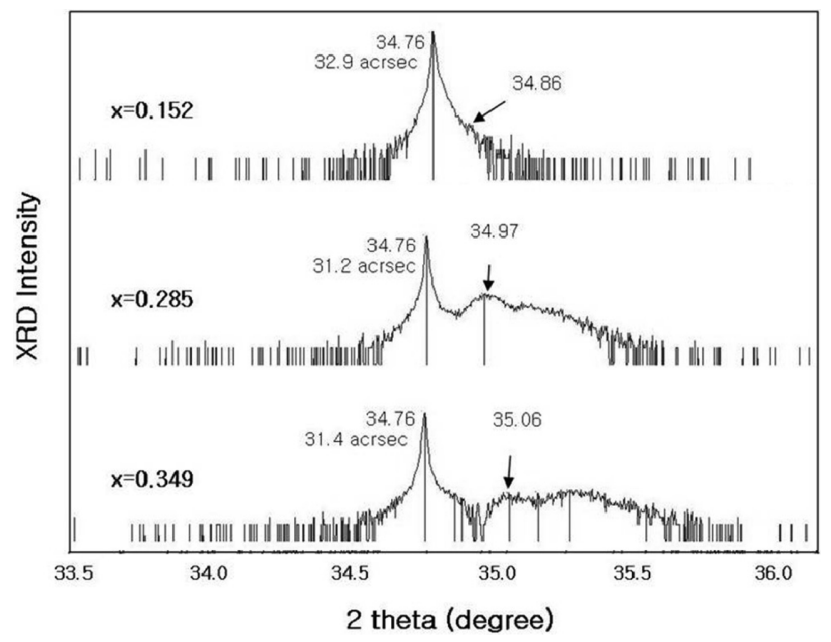

Fig. 3. The results of XRD measurement of $\mathrm{AlGaN}$ active layer by change the $\mathrm{Al}$ compositon.

Table 1

The transition of $\mathrm{Al}$ composition, lattice constant and wavelength by change the $\mathrm{Al}$ content

\begin{tabular}{lllll}
\hline $\begin{array}{l}\mathrm{Al} \\
\text { contents } \\
(\mathrm{g})\end{array}$ & $\begin{array}{l}\text { X-ray diffraction } \\
\text { angle }(0002) \\
(\text { degree })\end{array}$ & $\begin{array}{l}\text { Lattice } \\
\text { constant of } \\
\text { c-axis }(\AA)\end{array}$ & $\begin{array}{l}\mathrm{Al} \\
\text { composition } \\
(\%)\end{array}$ & $\begin{array}{l}\text { Wavelength } \\
(\mathrm{nm})\end{array}$ \\
\hline 0 & 17.38 & 5.185 & 0 & 435 \\
0.1 & 17.43 & 5.143 & 0.152 & 420 \\
0.4 & 17.49 & 5.127 & 0.285 & 410 \\
0.6 & 17.52 & 5.117 & 0.334 & 390 \\
\hline
\end{tabular}

면의 $2 \theta$ 측정값을 $\mathrm{Bragg}$ 법칙과 육방정계의 면간 지수 를 구하는 공식에 적용하여 c축의 격자상수를 구하였다. $\mathrm{Al}$ 첨가량에 따른 격자상수의 변화와 X-ray 회절 각도 를 Table 1에 나타내었다. 구해진 $\mathrm{AlGaN}$ 의 격자상수로 부터 $\mathrm{Al}$ 첨가량이 높아질수록 $\mathrm{AlGaN}$ 결정의 격자상수가 감소함을 알 수 있었다. 또, XRD 측정 결과로부터 얻어 진 c축의 격자상수를 식(1)에 대입하여 $\mathrm{Al}$ 조성비를 구 할 수 있었다[6]. 그 결과 혼합소스의 $\mathrm{Al}$ 함량이 증가할 수록 $\mathrm{AlGaN}$ 층의 $\mathrm{Al}$ 조성 역시 증가함을 보았다.

$$
\mathrm{x}(\text { composition })=\frac{\mathrm{c}_{\mathrm{AlGaN}}-\mathrm{c}_{\mathrm{GaN}}}{\mathrm{c}_{\mathrm{AlN}}-\mathrm{c}_{\mathrm{GaN}}}
$$

활성층에서 $\mathrm{Al}$ 의 조성 변화에 따른 발광 변화를 알기 위해 EL 측정을 하여 그 결과를 Fig. 4와 Table 1에 나 타내었다. 주입전류 $20 \mathrm{~mA}$ 에서 EL 측정결과 Fig. 4에 나타낸 바와 같이 $\mathrm{GaN}$ 는 $435 \mathrm{~nm}, 0.1 \mathrm{~g}$ 의 $\mathrm{Al}$ 이 첨가된 $\mathrm{AlGaN}$ 활성층은 $420 \mathrm{~nm}, 0.4 \mathrm{~g}$ 의 $\mathrm{Al}$ 이 첨가되었을 때

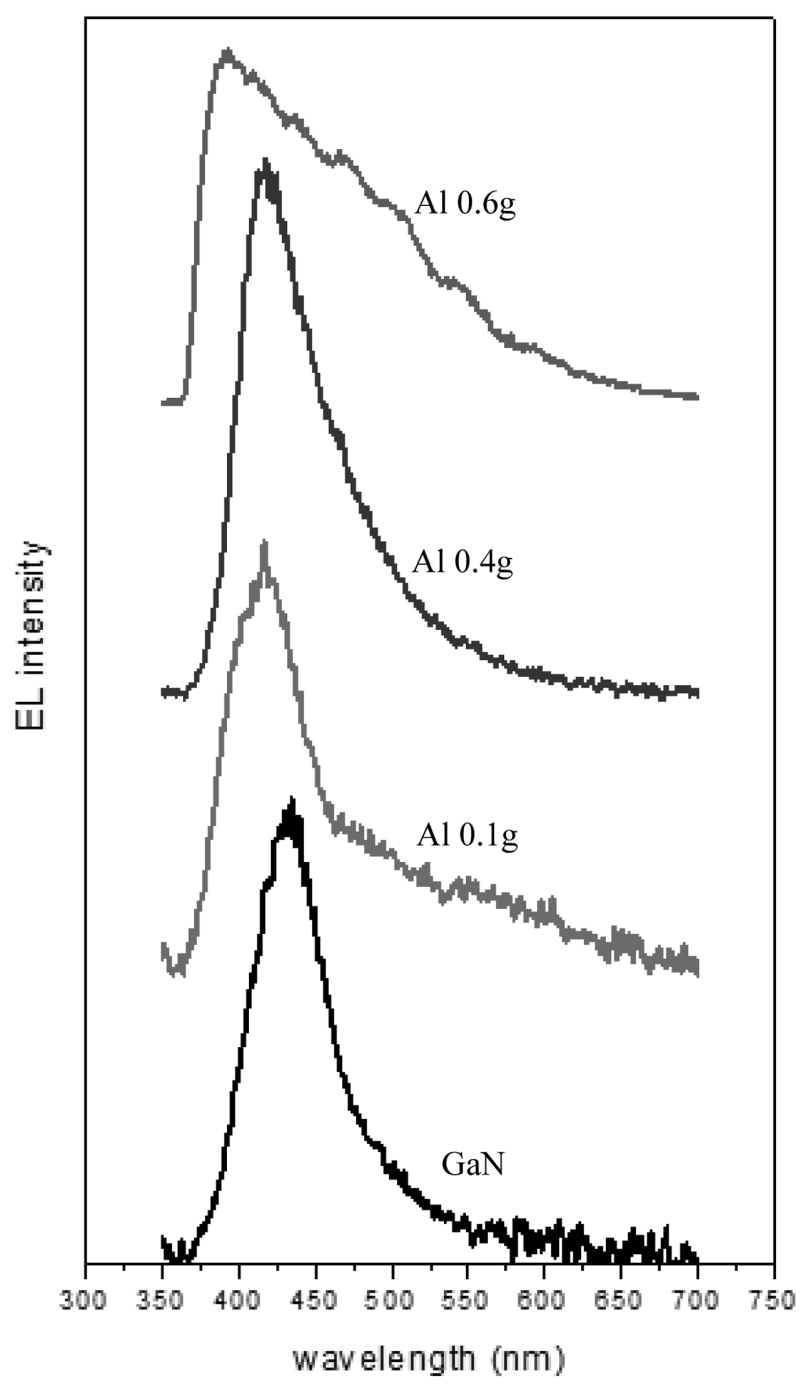

Fig. 4. The EL spectra by change the $\mathrm{Al}$ contents. 


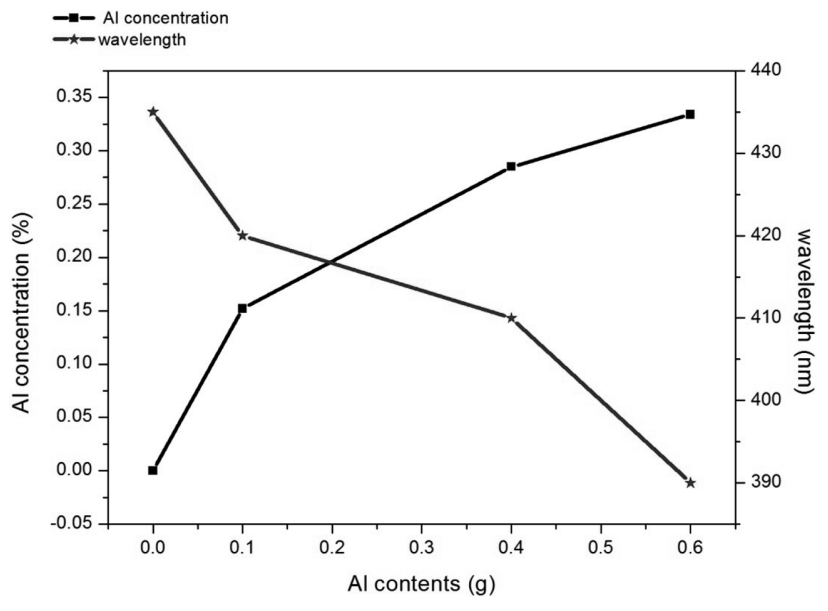

Fig. 5. The transition of $\mathrm{Al}$ composition and wavelength by change the $\mathrm{Al}$ contents.

는 $410 \mathrm{~nm}, 0.6 \mathrm{~g}$ 의 $\mathrm{Al}$ 이 첨가되었을 때에는 $390 \mathrm{~nm}$ 에 서 발광 스펙트럼을 보였다. 스펙트럼에서 보이듯이 $\mathrm{Al}$ 의 첨가량이 증가할수록 발광 파장이 단파장으로 이동하 는 현상을 보였다. $\mathrm{Al}$ 을 $0.6 \mathrm{~g}$ 추가한 경우에서의 $\mathrm{EL}$ 결 과에서는 $430 \mathrm{~nm}$ 부근에서 약간의 peak가 보였는데 본 실험에서 $\mathrm{GaN}$ 를 활성층으로 가지는 $\mathrm{DH}$ 의 $\mathrm{EL}$ 측정결 과 peak이 $435 \mathrm{~nm}$ 에서 보인 것으로 미루어 볼 때 $\mathrm{GaN}$ 의 peak으로 추측되며 성장된 $\mathrm{AlGaN}$ 박막에서 $\mathrm{Al}$ 이 균 일하게 분포되지 못하여 부분적으로 $\mathrm{GaN}$ 가 있기 때문 인 것으로 추측된다. 이러한 것으로부터 미루어 볼 때 혼합소스법을 이용하여 $\mathrm{Al}$ 의 조성비는 조절이 가능해 졌으나 $\mathrm{AlGaN}$ 의 균일도를 위해서는 $\mathrm{Al}$ 의 적절한 조성 비가 중요하다고 생각된다.

혼합소스내의 $\mathrm{Al}$ 함량 변화에 따른 발광파장의 변화 와 $\mathrm{Al}$ 조성비 변화를 Fig. 5에 나타내었다. Fig. 5의 결 과로부터 혼합소스에 첨가하는 $\mathrm{Al}$ 함량을 조절함에 따 라 성장된 $\mathrm{AlGaN}$ 층의 $\mathrm{Al}$ 조성비를 조절 할 수 있으며 그에 다른 발광파장 또한 조절이 가능함을 확인하였다.

\section{4. 결 론}

기존의 $\mathrm{HVPE}$ 법과 달리 $\mathrm{Ga}$ 금속과 $\mathrm{Al}$ 금속을 직접 혼합하는 혼합소스 $\mathrm{HVPE}$ 법으로 undoped- $\mathrm{GaN} / \mathrm{Al}_{2} \mathrm{O}_{3}$ 기판 위에 $\mathrm{AlGaN}$ 층을 성장하였다. 성장온도 $1090^{\circ} \mathrm{C}$ 에 서 금속 $\mathrm{Ga} 20 \mathrm{~g}$ 당 금속 $\mathrm{Al}$ 의 첨가량을 $0.1 \mathrm{~g} \sim 0.6 \mathrm{~g}$ 까지 조절하여 성장하였다. 성장된 시료의 XRD 측정을 통해 격자상수 값을 얻을 수 있었다. 이로부터 성장된 $\mathrm{AlGaN}$ 층이 wurtzite 구조임을 확인하였고 혼합소스의 $\mathrm{Al}$ 함유 량이 증가함에 따라 격자상수가 감소함을 보았다. Vegard 법칙을 이용해 $\mathrm{AlGaN}$ 층에서 $\mathrm{Al}$ 의 조성비를 구 할 수 있었는데, $\mathrm{Al}$ 함량이 증가할수록 조성비 또한 증가
함을 보았다. 발광특성을 보기 위해 실시한 $\mathrm{EL}$ 측정을 통해 $\mathrm{Al}$ 의 조성이 증가할수록 밴드갭 에너지가 증가하 여 발광파장이 짧아짐을 알 수 있었다. 앞선 결과들로부 터, 기존의 HVPE법이 아닌 혼합소스 HVPE법을 이용 한다면 $\mathrm{Al}$ 의 조성을 보다 쉽게 조절할 수 있고 그에 따 라 원하는 파장대의 발광이 가능한 활성층을 가진 양질 의 LED 소자를 제작할 수 있을 것으로 기대된다.

\section{감사의 글}

본 연구는 지식경제부 산업원천기술개발사업(과제번호: 10037416 , 해양 LED 융합기술지원 기반구축 및 상용화 기술개발)으로 지원된 연구임.

\section{참 고 문 헌}

[ 1] Motoaki Iwaya and Shinji Terao, "Suppression of phase separation of AlGaN during lateral growth and fabrication of high-efficiency UV-LED on optimized AlGaN", Journal of Crystal Growth 237-239 (2002) 951-955.

[2] A.A. Allerman and M.H. Crawford, "Growth and design of deep-UV (240 290 nm) light emitting diodes using AlGaN alloys", Journal of Crystal Growth 272 (2004) 227.

[3] I.-S. Seo and S.-J. Lee "The role of AlN buffer layer in $\mathrm{Al}_{\mathrm{x}} \mathrm{Ga}_{1-\mathrm{x}} \mathrm{N} / \mathrm{GaN}$ heterostructures with $\mathrm{x}$ from 0.35 to 0.5 grown on sapphire (l $\left.\begin{array}{llll}0 & 0 & 0 & 1\end{array}\right)$ ", Journal of Crystal Growth 241 (2002) 297.

[4] T. Namazu and S. Inque, "Characterization of single crystal silicon and electroplated nickel films by uniaxial tensile test with in situ X-ray diffraction measurement", Fatigue Fract. Engng. Mater. Struct. 30 (2007) 13.

[5] A. Krost and J. Blasing, "Nearly strain-free AlGaN on ( $\left.\begin{array}{llll}0 & 0 & 0 & 1\end{array}\right)$ sapphire: X-ray measurements and a new crystallographic growth model", Journal of Crystal Grwoth 221 (2000) 251.

[6] A. SH. Hussein and Z. Hassan, "Effect of Al mole fraction on structural and electrical properties of $\mathrm{Al}_{\mathrm{x}} \mathrm{Ga}_{1-\mathrm{x}} \mathrm{N} /$ $\mathrm{GaN}$ heterostructures grown by plasma-assisted molecular beam epitaxy", Applied Surface Science 257 (2011) 4159.

[ 7 ] H. Ashraf and J.L. Weyher "Thick GaN layers grown by HVPE: Influence of the templates", Journal of Crystal Growth 310 (2008) 3957.

[ 8 ] B. Lucznik and B. Pastuszka, "Deposition of thickGaN layers by HVPE on the pressure grown GaN substrates", Journal of Crystal Growth 281 (2005) 38.

[9] Yamina Andre and Agnès Trassoudaine, "Low dislocation density high-quality thick hydride vapour phase epitaxy (HVPE) GaN layers", Journal of Crystal Growth 306 (2007) 86.

[10] S.T. Kim and Y.J. Lee, "Preparation and properties of free-standing HVPE grown GaN substrates", Journal of Crystal Growth 194 (1998) 37. 